\title{
BREVE DESCRIPCIÓN GEOGRÁFICA, HISTÓRICA, SOCIAL, ECONÓMICA Y CULTURAL DE LA SIERRA LIMEÑA: SAN PEDRO DE CASTA
}

tic. Pedre P. Soto Canales

\section{Descripción geográfica}

La comunidad campesina de San Pedro de Casta se encuentra bajo la jurisdicción de la provincia de Huarochiri, la cual tiene como capital a la ciudad de Matucana. Elevada a la condición de distrito, Casta se encuentra categorizada como «villas siendo uno de los 32 distritos que conforman el departamento de Lima

A dicha comunidad se logra llegar por medio de la carretera Lima-Chosica (Carretera Central). El recorrido desde Lima hasta San Pedto de Casta es de 80 kilómetros, con un tiempo aproximndo, segun las condiciones del camino, de 6 a 8 horas.

Sus límites son: por el Norte, con las comunidades de Huachupampa y San Juan de Iris; por el Sur, con las comunidades de Callahuanca y San Mateo de Obtao; por el Este, con Matucana; por el Oeste, con San Antonio de Chaclla y Santa Eulalia. Sus coordenadas geográficas son: latitud Sur $11^{\prime \prime} 45^{\prime} 18^{\prime \prime}$, mientras que su latud Este es de $76^{\circ} 35^{\prime} 39^{\prime \prime}$; con una superficie de 79,91 kilómetros cuadrados y una densidad poblacional de 14,2 habirantes por kilometro cuadrado, 


\section{Pedro P, Soto Canales}

La comunidad de San Pedro de Casta tiene una alatud de $3,180 \mathrm{msnm}$, ubicăndose asi en la región Quechua, presentando también territorios de cultivos en otras alturas como son: Yunga y Suni. Las partes más altas están destinadas al pastoreo y se ubican a los 4,600 msnm y corresponden a la región Jalca o Puna. Ia comunidad abarca cuatro microclimas que son: cálido, termplado, frio moderadoy frio intenso. La temperatura oscila entre $10^{\circ}$ a $21^{\circ}$ grados, y en las noches baja hasta cerogrados.

El pueblo se encuentra dividido en barrios entre los cuales tenemos: Patapata, Buenos Aires, Carmen Alto y Cuchicuchi; mientras que los comuneros se encuentran organizados en dos parcialidades: Yañac y Yacapar. El nombre de dichas parcialidades parece provenir de los únicos ayllus existentes en Casta, según la visita de 1752 al Repartimiento de Chaclla de la Doctrina de Casta. (Ver esquema N. ${ }^{a}$ 1.) Cada una de estas parcialidades tiene su respectiva casa o "wayronas en donde se reunen para la organización y convites, especialmente en la fiesta patronah, según la parcialidad a la que le toque durante el año.

En lo que se refiere a la infraestructura, las calles son empedradas y con grandes inclinaciones. La mayoria de las viviendas son de material noble (ladrillos y calaminas), perduran todavia las construcciones de piedras con techo de ichu y adobe, piedras que, según la observación de Julio C. Tello ${ }^{1}$, fueron extraidas de los restos arqueológicos que aún existian alrededor de la comunidad:

... A cuatro kilómetros de Laksa, y descendiendo a lo largo de la colina, se halla este pueblo artuinado (wila kachina). Apenas quedan algunos muros, los que pronto desaparecerán totalmente porque de aquí también sacan piedras para utilizarlas en las construcciones de Casta...

En la Plaza Mayor encontramos los principales locales públicos y administrativos: la Municipalidad, el local comunal, la iglesia matriz y dos locales de alojamiento para los visitantes que llegan a conocer Markahuasi. Ademăs, la comunidad

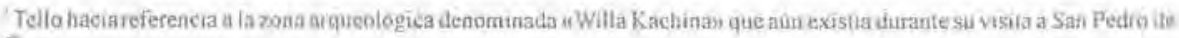
Casta 


\section{BREVE DESCRIPCIỎN GEOGRĀFICA, HISTŌRICA, SOCIAL, ECONÖMICA Y CULTURAL DE LA SIERRA LIMENAA: SAN PEDRO DE CASTA}

cuenta con ura Posta Médica, dos centros educativos, el cementerio y, por último, el local de la única industria que existió en San Pedro de Casta, la Cooperativa Quesera, que fue el resultado del convenio entre el gobierno de Suiza y la Comunidad Casteria en la dêcada de los 70 para la producción de quesos, en la que todos los comuneros eran socios. Este proyecto fracasó; luego, entre los años 1992 y 1993, fue utilizado por el Ejército como puesto militar a consecuencia de supuestos atentados contra la bidroeléctrica de Huinco. Lamentablemente, las autoridades de San Pedro de Casta pidieron la salida de dicha base militar por abaso de autoridad. Actualmente, en dicho local funciona la Oficina de Agencia Agraria.

Entre los servicios que encontramos en la comunidad tenemos: el alumbrado público y privado, gracias a su situación geográfica cercana al anexo de Huinco (hidroeléctrica). También existe el servicio de agua pública a través de pilones, que traen dicho elemento desde uno de los manantiales cercanos del rio Karhuayumac. (No existe el servicio por parte de SEDAPAL.) La seguridad policial es solicitada por las autoridades a utras localidades, especialmente para las celebraciones comunales, con la finalidad de guardar el orden público. En lo que se refiere a medios de comunicación, encontramos en la comunidad una antena parabólica y la presencia de un teléfono público ubicado en la plaza principal, ambos adquiridos en los últimos años por la comunidad.

\section{Reseña histórica}

Durante el 900-1476 d. C., la sierra central se caracteriza porque la estrategia de subsistencia es mediante el control intensivo del trabajo basado en la agricultura y la ganaderia. Las formas politicas que aparecen son reinos y señotios independientes, los pueblos están dispersos y sólo se reúnen para celebrar sus Fiestis o para realizar acciones bélicas entre si.

En la actual provincta de Huarochiri, era una época de luchas y rivalidades entre cmtas vecinas, de éstas son dos las que sobresalieroti y que serian la base del fuzuro San Pedro de Casta: los yungas y los yauyos. 


\section{Pedro P. Soto Canales}
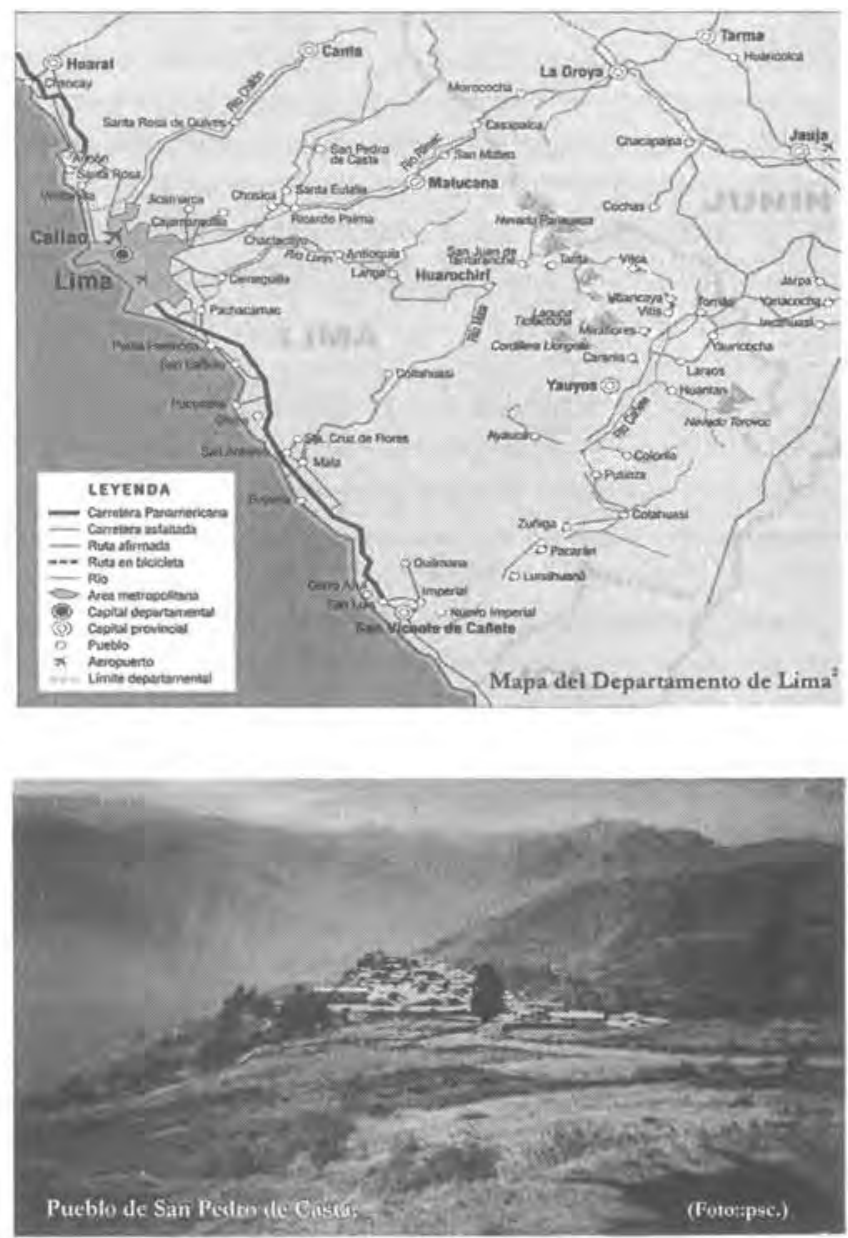

\footnotetext{
${ }^{2}$ Fuente; diario la «Repuiblica»,
} 


\section{BREVE DESCRIPCIŌN GEOGRÁFICA, HISTÓRICA, SOCIAL, ECONỐMICA $Y$ CULTURAL DE LA SIERRA LIMEÑA: SAN PEDRO DE CASTA}

Huarochiri habia sido ya habitado desde el Intermedio Temprano por los yungas, los cuales estaban constituidos por varios señorios. Según Cieza de León, se les Llamaba así porque moraban los llanos y costas del Perú, es decit, las tierras cálidas (es el caso del seriorio Colli u Collique). De todas las divinidades yungas sobresalía la denominada Wallallo, que habitaba en las alturas y era el señor de las cosechas al cual se le rendía culto y tributos mediante fiestas. Vivian de la pesca, la agricultura $y$ del intercambio comercial. Pero con el fin de asegurat el suministro de agua que nacía en las altas cabeceras de los valles comenzaron a incursionar en la sierra limeña.

Por el año 1100 d. C., Huarochiri es invadida por los yauyos, quienes optan por desalojar a los yungas de las bocatomas de las lagunas abicadas en las alturas, llegando así a dominar las actuales provincias de Huarochirí y Yauyos:

... Al saber los Yauyos que las terras costeñas se regaban con aguas que bajaban de sus territotios creian que era derecho adquirido que estaban listos defender con las armas...

(Rostworoswky 1977: 82)

Los yauyos eran gente guerrera que vivian especialmente de la agricultura y la ganaderia, eran ugrupos serranos que proveníat del sur; de origen aymarás (Gelles 1986: 135). Su divinidad suprema era Pariacaca que habitaba en las alturas de Huarochiri (al igual que el ptincipal curaca Yauyo), Al set vencidos los yungas por los serranos optaron por migras a otros territorios, aunque varios se quedaron a vivir en los pueblos de sus vencedores a carmbio de adorar a Paracaca y de «cooperar en el mantenimiento de los sistemas hidráulicos\%. (Gelles 1986: 108).

El nuevo territorio de los yauyos comprendia Anan Yauyos (alto Yauyos), que era la sierra del sur y Lorin Yauyos (bajo Yauyos), que era la sierra del norte. En esta últíma se encontraban tres importantes curacazgos Yauyos: Chaccalla (Chaclla), Kurapuma (Carampoma) y Casta. Según los casteños actuales, la palabra Casta proviene de «Kashas que era el nombre de un ayllo importante durante la formación de San Pedro de Casta colonial. 


\section{Pedro P. Soto Canales}

Según Tello, la casta prehispánica se encontraba dividida en akuris», que eran confederaciones de poblados o ayllus unidos por la posesión y dominio de tierras (sectores agrarios) y por la idea de un antecesor común que era hijo del rayo del
KURIS (distritos agrarios)
Kuri Pata Kuri
Soqta Kuri
Koway Kuri
Punku Wanka Kuri
Kairi Achin Kuri
Pampa Kocha Kuri

cual tomaban su nombre y se creian descendientes, y que se encontraba encantado en algún peñón dentro del sector agrario correspondiente. El tipo de gobierno era gerontocrático, es decir, gobierno de los ancianos.

De todos los «kuris» existentes en la casta prehispánica, el más importante y con mayor autoridad sobre los demás era Soqta Kuri que se ubicaba en Markahuasi. Además, Tello proponia que San Pedro de Casta (colonia) se debió construir en los terrenos del sector agrario de Koway Kuri. (Tello 1923: 481-491; 504-505). En conclusión, el término xkuris hace referencia a una o varias etnias (grupo de ayllus) concebidas como descendientes de Pariacaca, todos los cuales se ubicaban

\section{PRINCIPALES AYLLUS PARA LA FORMACIÓN DE CASTA COLONIAL}

Koway Kuri Pampa Kocha Kuri Kairi Achin Kuri

Koway

Waya Kocha

Achin (?)

Wila Kachina

Kasha

Opika 


\section{BREVE DESCRIPCIÕN GEOGRẢFTCA, HISTÓRICA, SOCIAL, ECONÕMICA \\ Y CULTURAL DE LA SIERRA LIMENA: SAN PEDRO DE CASTA}

en las cimas de las cadenas de cerros (Echeandia 1981: 2224). Acrualmente los casteños llaman kkuris a los cerros.

En el periodo Inca, especialmente en tiempos de las conquistas de Tupac Inca Yupanqui, los yauyos se anexaron al incanato en forma pacifica volviéndose sus aliados, hecho que impresionó a los cuzqueños, los cuales tipificaban a los yauyos como gente belicosa. De esta manera, los curacazgos yauyos de Huarochin' siguieron teniendo autonomia politica, religiosa y económica a cambio de tributar a los cuzqueños. El único cumcazgo conflictivo fue el de Chaccalla, que se enfrentó contra los yungas de los Cantamarca (Canta) y los Colli (Collique); por último, los tres fueron sometidos de manera violenta por los cuzqueños.

Pasados los momentos de la conquista y en pleno periodo colonial, es con el virrey Don Francisco de Toledo (1569-1581) que se hicieron, en Huarochiri, las primeras reducciones de indios, obra que fue encargada a don Diego Dávila Briceño, para ello Huarochiri comprendia cinco encomiendas ${ }^{3}$ :

La encomienda de Chaccalla, que a su vez comprendia los territorios entre la sierra alta de la quebrada de Santa Eulalia y del rio Chillón. En ella se encontraban los siguientes pueblos reducidos:

1. Mancos y Laraos

2. Yauyos (Atun Yauyos)

3. Huarochiri

4. Mama

5. Chaccalla (Chaclla)

Actualmente perdura en los habitantes de San Pedro de Casta los nombres de aquellos ayllus que, al ser reducidos, dieron origen al pueblo (ver entrevistas)":

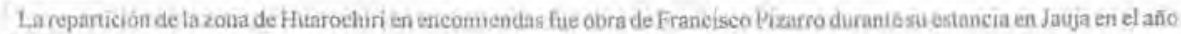
de 1534

'Erturevistasrealizadas a los cormụctos casteños, entri agosto y octubre del año 2000 
Pedro P. Soto Canales
1. Santa Olalla de Collao
(Santa Eulalia)
2. San Jerónimo de Puna
3. San Francisco de Chaccalla (Chaclla)
4. Santiago de Carampoma
(Kurapuma)
5. San Pedro de Casta
(Kasha\{?\})

... Casta proviene de cuatro pueblos... que se reúnen un dia los jefes de pueblo... entonces llegaron a vivir acá... habian centros poblados que tienen origen de nombre quechua por ejemplo: Achin , opika, guallacocha y Kasha...

Sr. Herbert Flores Rojas (Alcalde)

... Dicen que San Pedro de Casta se formó de cuatro ayllus... de Guallacocha, Achin, Opika y Kasha... o sea en el año 1540... habian más pera solamente esos cuatro han sido los que han poblado Casta...

Sra, Herminda Bautista Obispo (Comedor)

... La comunidad se origina de la concentración de los pueblos de: Guallacocha, Achin, Opika; que estaban alrededor del pueblo que se creó... hubo "Reducción" los trajeron para acá y los bautizaron con el nombre de San Pedro... y Kasha...; y ortos hay algunos pueblitos chiquitos... todo esto fue ordenado por el virrey Don Francisco Toledo y llevado a cabo por el Corregidor de Huarochirí Don Diego Dávila en $1560 \ldots$

St. Walter Medina Obispo (Corregidor)

La confusión aparece en la fecha de creación del pueblo, confusión que ta encontramos inclusive en los documentos oficiales de la comunidad. La respuesta del St. Walter Medina estuvo basada en el Anteproyecto del Reglamento de la Comunidad (Disposiciones Generales, Art. 2). Si tenemos en cuenta que Toledo comienza su gobierno en 1569 , las fechas anteriores están fuera de lugat. 


\section{BREVE DESCRIPCIÖN GEOGRÁFICA, HISTÓRICA, SOCIAL, ECONOMMICA \\ Y CULTURAL. DE LA SIERRA LIMEÑA: SAN PEDRO DE CASTA}

Probablemente, y como lo propone Gentile (1981:178), la reducción de San Pedro de Casta se diodel año $1571^{5}$.

Estos pueblos reducidos estuvieron bajo la labor evangelizadora, primero de los Dominicas y luego por los Jesuitas; después fueron doctrinados por curas seculares y clérigos (Carcelen 1996: 210). Para el año 1586, el Repartimiento de Chaclla estaba dividido en dos «doctrinas» y media las cuales eran:
1. Santiago de Carampoma
2. Chaclla, Puna y Casta
3. Santa Eulalia

Ayllus que conformaban el pueblo de San Pedro de Casta durante la Colonia (siglos XVI-XVIII)
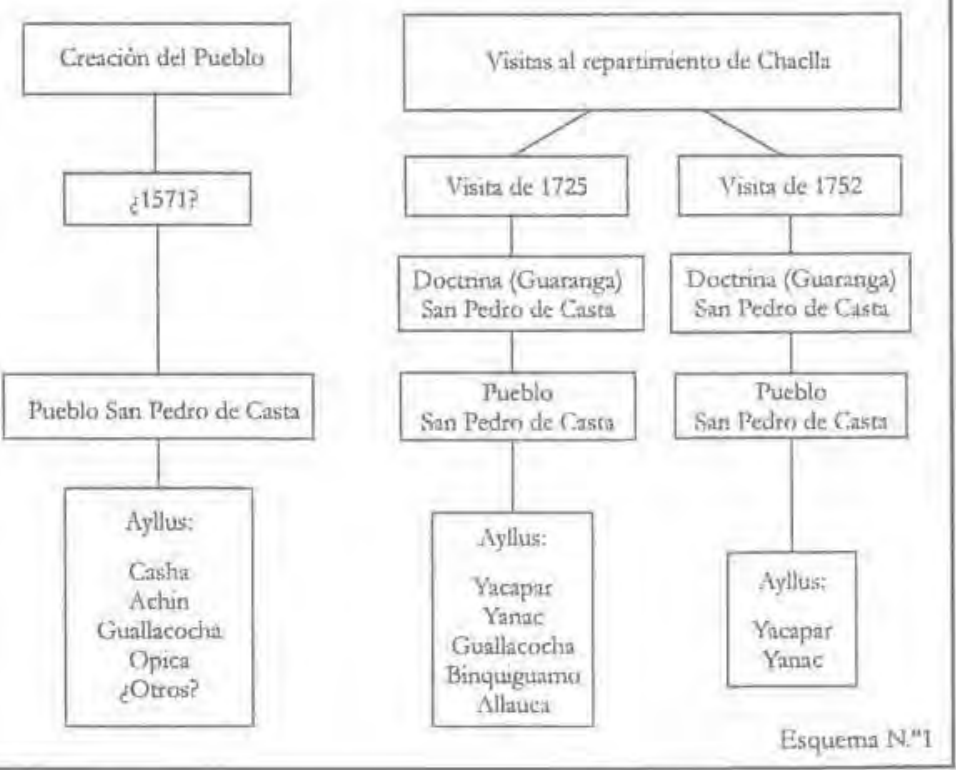

E. antropologo Paùl Gelles proporie como fecha de fundacion el año 1586. ( 1986: 106), 
Estas modificaciones se daban a causa de las epidemias, guerras civiles, hambruna, trabajo en las minas, etc. Para 1725, el repartimiento de Chaclla comprendia 11 pueblos, y para el año 1752 aumentó a 12 pueblos, stempre entre ellos San Pedro de Casta.

Después de treinta y seis años de haber comenzado la vida republicana (1821) y según ley con fecha 2 de enero de 1857 , en pleno segundo gobierno de don Ramón Castilla, San Pedro de Casta fue reconocida oficialmente como distrito, teniendo en ese momento como anexos a Otao, Huachupampa, Iris y Callahisanca (actuales distritos de Huarochiri).

Durante el siglo XX, San Pedro de Casta es reconocido, primero como kcomunidad indígenas siendo presidente de la República don Óscat R. Benavides, mediante Resolución Ministerial del 27 de octubre de 1936. Luego, en cumplimiento de la Resolución de SINAMOS N. ${ }^{2} 0518$ del 24 de septiembre de 1973, se aprueba el plano de la comunidad reconociéndola como comunidad campesina al año siguiente (1974). Teniendo como anexos (hasta la actualidad) a los pueblos de Huinco, San Antonio de Cumpe y San Juan de Mayway (el de menor poblado), según el proyecto del gobierno militar del general Juan Velasco Alvarado durante la Reforma Agraria

\section{Realidad social, educativa y económica}

La sociedad casteña ha aumentado en referencia a otros años, siendo su población actual de 1800 habitantes, aproximadamente. En ella, la población masculina comprende el $51 \%$, mientras que la población femenina el $49 \%$; por la tanto, la distribución de la población, según el sexo, està efi un punto equilibrado. Si hablamos de la población distribuyéndola por periodos o etapas del desarrollo humano, los resultados son los siguientes: el mayor sector de la población lo comprende aquellas personas que están en la etapa adulta, en segundo lugar la población infante, en tercer lugar están los adolecentes y en cuarto lugar las personas comprendidas enla etapa de la ancianidad.

Los principales impedimentos físicos y psicológicos que sufren los pobladores de 


\section{BREVE DESCRIPCIÓN GEOGRĀFICA, HISTÓRICA, SOCIAL, ECONÓMICA Y CULTURAL DE LA SIERRA LIMENAA: SAN PEDRO DE CASTA}

San Pedro de Casta son la sordera total, la ceguera total, retardo y alternciones mentales; estos impedimentos se presentan en baja escala entre los adolescentes y ancianos, mas no en los infantes y nuños.

El $92 \%$ de la población profesa la fé católica, aunque en la actualidad se nota la presencia de dos templos no católicos pertenecientes a la Iglesia Alianza y Misionera y a la Iglesia Adventista, organizaciones que han comenzado su labor evangelizadora en la comunidad a partir de la ausencia de orden o comunidad religiosa católica alguna que tenga a su cargo la administración del templo matriz existente y de la evangelización del pueblo.

En lo que se refiere a la cultura, la educación de San Pedro de Casta se da en dos formas: una educación formal que es la impartida oficialmente por las escuelas y la educación informal que se da al nivel de «familia-comunidad», que es la trasmisión de conocimientos prácticos de padres a hijos thediante las costumbres, fiestas, ritos, etc. y que influyen especialmente en la actividad laboral de la comunidad. (Jara 1975: 68).

Sobre el nivel educativo (Gráfico N: 1), el $60 \%$ de la población sólo ha logrado alcanzar el nivel primario, nos referimos a la población adulta; mientras que, en segundo lugar, tenemos un $27 \%$ en el nivel secundario, compuesto por los adolescentes, $y$ en tercer lugar un $12 \%$ de la población que ha logrado alcanzar estudios superiores fuera de la comunidad, siendo las profesiones preferenciales Educación, Mecánica Automotriz y Enfermeria. Dicha situación se debe a que el primer centro de estudios de la comunidad viene furcionando desde hace más de 50 años y otorga solamente el nivel primatio. Hacia 1979 comienza a funcionar el nivel secundario (C. E. wJosé Carlos Mariateguim), y en 1982, el nivel de inicial (Centro Educativo N. ${ }^{\circ} 398$ ).

El $89 \%$ de la población sabe leet y escribir, mientras que el $11 \%$ no, to que corresponde a personas entre cinco a nueve años, $y$ de cuarenca a șesenta y enco años de edad (Gráfico $N^{\circ}{ }^{\circ}$ 2), especialnente en la población femenina. El idioma que habla la comunidad es el castellano. 


\section{Pedro P. Soto Canales}

La economia de San Pedro de Casta descansa princapalmente en la producción agricola, que es la actividad fundamental de la comunidad. Por la misma realidad geográfica no se hace uso de maquinaria alguna sino de la tecnologia básicamente tradicional para trabajar los diferentes pisos ecológicos: herramientas de mano como la taklla, el pico, la sapa, el trinche, la lampa, etc. son las más utilizadas para el cultivo especialmente de la papa, maiz, habas, ollucos, mashuas, ocas, frijoles. En algunos casos se hace uso del abono del cuy como fertilizante.

El principal personaje de la actividad laboral es el scomuneron, llamado asi al miembro de la comunidad que goza de la propiedad comín de los medios de producción (entrevista):

... para ser comunero se necesita ser hijo de comuneros o por asimilación... un foráneo puede casarse con una hija del pueblo o también una foránea con un hijo... y tener residencia estable en la comunidad no menor de cinco años.. y curmplir sus obligaciones y mandatos de la comunidad con sus costumbres.., la asamblea lo acepta como comunero... y hacer un pago como derecho de ingreso por las obras hechas por la comunidad...

Sr. Hedilberto Rojas Jiménez (presidente de la Comunidad)

Las therras de cultivo en Casta se encuentran distribuidas en sectores agrarios (sistema de distribución rotativo). Anualmente se cultiva un sector, por lo tanto, los demás sectores agrarios descansan entre cuatro a cinco años. Cada sector, a su vez, se civide en parcelas. Cada comunero tiene su parcela (una hectárea) en cada uno de los sectores agrarios.

\begin{tabular}{|}
\hline PRINCTMLES SECTORES AGRARTOS \\
Guallacocha \\
Laco \\
Potreros $(1$ y 2$)$ \\
Cercano \\
Mayway
\end{tabular}




\section{BREVE DESCRIPCIÖN GEOGRÁFICA, HISTÓRICA, SOCIAL, ECONÓMICA $Y$ CULTURAL DE LA SIERRA LIMEÑA: SAN PEDRO DE CASTA}

El comunero en San Pedra de Casta también obtiene el terreno de cultivo (parcela) por herencia o solicitando a la asamblea comunal un terreno abandonado. Las aguas para el regadio tienen como otigen las lagunas situadas a más de $3500 \mathrm{msnm}$ como también el río Karhuayumac y el manantial Kungiac. Además, la comunidad trabaja en base a pequenas represas y acequias de filtración, muchas de ellas de origen prehispánico. La distribución del agua se realiza por turnos, diariamente, y por un tiempo de cinco a seis boras, y según el caudal se riega las parcelas de 10 a 15 comuneros. Para ello se debe pagar a los vigilantes de los reservorios por dicho servicio, todo esto supervisado por la asamblea comunal.

Como segunda actividad económica tenemos el pastoreo. El ganado está compuesto por vacas, ovejas y cabras. El pasto en San Pedro de Casta crece especialmente en las faldas de los cerros $y$ es de mucha importancia en la alimentación del ganado. Junto al pastoreo encontramos la fiesta de la kherranzan, en la que el comunero marca a los animales de su propiedad.

El poblador de San Pedro de Casta comienza sus actividades dentro de su comunidad desde muy temprana edad ayudando a sus padres, tal como lo había observado el educador Alfonso Jara Salas:

... los niños casteños, desde temprana edad, recorren las diversas parcelas que pertenecen a la familia, cuyo origen de posesión se pierde en el tiempo, de tal manera, ellos aprenden a diferenciar progresivamente sus parcelas, según los productos que sacan de ellas...

(Jara 1975: 16)

La actividad laboral del poblador Casreno comienza a los seis años de edad, aproximadamente. En San Pedro de Casta, actualmente, la población económicamente activa comprende un $33 \%$ de la población mayor de seis años, y la económicamente no activa está conformada por el $67 \%$, entre aquellas personas que están encargadas del cuidado del hogat, estudiantes, jubilados, pensionistas, etcétera. 


\section{Pedro P. Soto Canales}

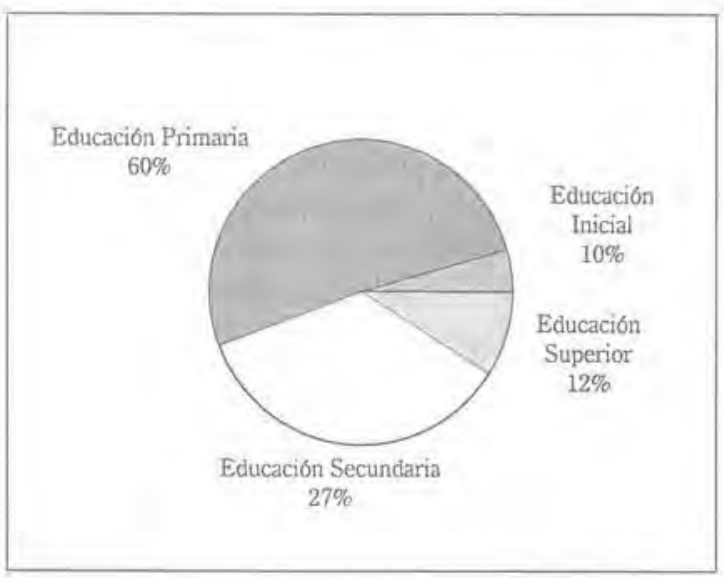

Grálico N. ${ }^{\circ}$

Niveles de estudios realizadus por los pobladores casteños.

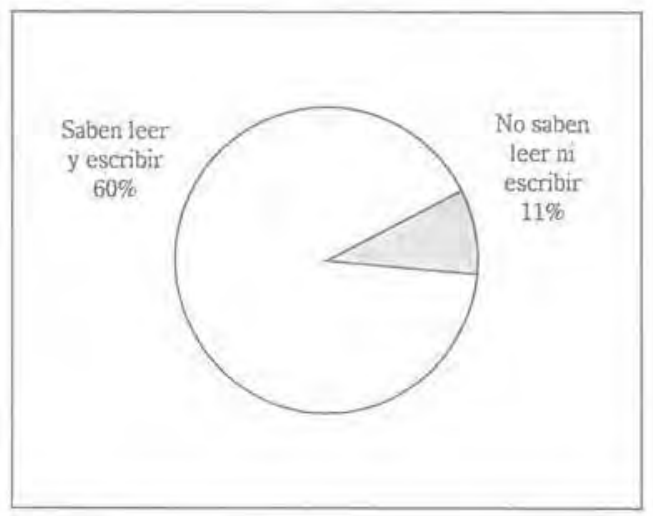

Gráliceo N: ${ }^{\circ} 2$

Sittiación de analfabetismo en San Pedra de Casta. 


\section{BREVE DESCRIPCIŌN GEOGRÃFICA, HISTÔRICA, SOCIAL, ECONÕMICA Y CULTURAL DE LA SIERRA LIMENAA: SAN PEDRO DE CASTA}

Quiero hacer referencia a una actividad que desde la década de los 80 ha tornado fuerza y viene sienda un canal de ingreso para la comuna en general, de donde sale una parte del capital económico para las obras públicas en San Pedro de Casta, me estoy refiriendo al turismo. La comunidad de San Pedro de Casta siempre recibe visitantes extranjeros y nacionales que llegan a la comunidad en busca de un lugar de descanso y para celebrar las fiestas comunales, pero especialmente para visitar la meseta de Markahuasi y ver los restos arqueológicos y piedras caprichosas que ella encierra.

Como he hecho referencia anteriormente, el doctor Tello, junto a Próspero Miranda, trabajaron en San Pedro de Casta, y en sus estudios hicieron referencia a los testos arqueológicos de la zona, entre ellos Markahuasi. Pero es el señor Daniel Ruzzo (de la Legión de los Masones), quien desde 1952, y por un espacio aproximado de nueve años, vivió en la meseta de Markahuasi y fue quien la promocionó, dándola a conocer como centto turístico esotética. Sus estudios se basaron en que dicha meseta, $y$ especialmente sus piedras, eran obras escultóricas ciclópeas de una cultura antidiluviana que llamó «masmà.

Entre sus colaboradores estaba la señorita Marcela Olivas Wiston, quien explica en uno de sus trabajos que las rocas de la meseta son de origen volcanico (andesitas), que contienen feldespato de calcio $y$ potasio, los cuáles el estat en contacto con el agua han erosionado dando lugar a figuras caprichosas, por lo tanto, son formaciones naturales (Olivas 1988).

Es asi como en la plaza principal de la comunidad encontramos la Oficina Central de Turismo en donde, además de propotcionar in formación, se da los servicios de consulta de mapas, fotogtafias, servicio de albergue y alojamiento temporal, guías, portadores, arrieros (incluye acémilas), guardinnes de campamento, etc. Pero, especialmente, en dicha oficina se lleva el control del registro de visitantes con el fin de administrar el ingresu de dichos servicios.

Siendo San Pedro de Casta un lugar muy rico en sitios arqueológicos y en tradiciones, no existe ningún tpo de apoyo de parte de entudades nacionales ni extranjeras. La comunidad tiene un Museo de Sitio, el cual se encuentra en el 
colegio de secundaria, en donde se presentan algunos restos óseos, de textilería y cerámica recogidos por los propios comuneros. Lamentablemente, el turismo para el comunero representa un ingreso directo, es por esto que observamos en la comunidad la falta de personas capacitadas para enseñat, explicar y proteger los bienes culturales:

... le falta a la comunidad, a los alumnos incluso, investigat más, es decir, dar más de uno mismo, piensan que turismo solamente es: llegaron turistas les alquilo mi burro, vendo agua arriba... pero conocen lo que son cuentos, mitos, lugares pero tienen dificultad de expresarlos... no tienen interés por su propia historia...

Directora (e) Isabel Cisneros Francia (Profesora de Historia y Geografia)

La última obra realizada por la comunidad casteña en unión de su alcalde es la construcción del Centro Recreacional «Viquil». Ubicado en el pie del monte de la jurisdicción de San Pedro de Casta, al margen izquierda del rio de Santa Eulalia, comprende un área de 16 hectáreas, sú construcción comenzó el 8 de abril de 1999 y su inauguración se llevó a cabo el 1 de mayo del año 2000. Por medio de esta obra, Casta espera tener ingresos económicos para el desarrollo comunal.

\section{Consideraciones finales}

1. Al igual que en otras comunidades de Huarochiri, San Pedro de Casta tiene como principal actividad económica la agricultura. Por la misma realidad geográfica en que se encuentra la comunidad no puede hacer uso de maquinaria pesada sino de herramientas de mano, practicando asi la tecnología tradicional andina, siendo un buen ejemplo de cómo en el mundo andino actual perduran las técnicas agrícolas e hidráulicas de tiempos ancestrales, las cuales fueron logros alcanzados por nuestros antepasados, antes de la llegada europea.

2. Toda organización y distribución, ya sea laboral o social que encontramos en la comunidad, tiene sus raices especialmente en la administración prehispánica. Asi, por ejemplo, la división de la comunidad en dos kparcialidades» hace referencia a 


\section{BREVE DESCRIPCIÓN GEOGRÄFICA, HISTÓRICA, SOCIAL, ECONÕMICA Y CULTURAL DE LA SIERRA LIMENAA: SAN PEDRO DE CASTA}

dos ayllus que subsisten pasado inclusive los tiempos de la colonia: Yacapar y Yanac. Según la tra dición casteña, la parcialidad de Yacapar corresponde a la parte alta (serranos), mientras que Yanac es la parte baja (costenos) del pueblo,

3. En la mentalidad de la comuna perdura la mitología local del intermedio tardio. Es asi como todo comuneto tiene presente las leyendas referentes a Wallallo, Soqta, Kuri, etc. Lo que llama la atenciỏn es que la tradición Yauyo sobre la divinidad de Pariacaca no está claramente presente en la comunidad. La principal causa es que San Pedro de Casta al ser pueblo ureducidon reunió a diferentes etnias, ayllus, etc. por lo cual algunas concepciones fueron perdiéndose en el tiempo mientras que otras perduran, especialmente de aquellos ayllus más sobresalientes (probabiemente los costeños).

4. La actual comunidad de San Pedro de Casta está compuesta, en su mayoría, por personas adultas que sólo han logrado alcanzar en estudios el nivel primario. Para el comunero, la educación comprende el conocimiento de su realidad geogrática y los medios de producción de su entorno (educación informal). Las útimas generaciones, es decir, los jóvenes han comenzado a migrar a las ciudades con la finalidad de seguir estudios superiores. Esto también trae como consecuencia que las fiestas, tradiciones, etc de la comuna se pierdan a se transformen a causa de nuevas influencias traídas de las ciudades.

5. Lamentablemente no se toma en cuenta la historia, los valores y los aportes culturales que han existido en la zona. Siendo San Pedro de Casta uno de los pocos pueblos de Huarochiri con contar con un centro de secundaria, se torna necesario modificar en cierta manera los programas oficiales de educación (tanto en primaria como en secundaria) e incluir en el curriculo de las asignaturas, especialmente de las Ciencias Sociales, temas relacionados a la realidad o entorno que les toca vivir. Especialmente la presencia de una historia local ayudaria no solamente al alumno sino a los comuneros a conocer la importancia de su existenca como comunidad, $5 a$ sea desde sus origenes como parte de una gran imperio llamado Tahuantinsuyo, como, en la actualidad, la de formar parte del Estado peruano, conocimiento de un pasado que lamentablemente la mayoria de ellos no conoce o va perdiendo. Una historia local con la característica de ser 


\section{Pedro P. Soto Canales}

dinámica, que siempre se encuentre renovándose, presentando a una sociedad que va cambiando pero sigue manteniendo sus tradiciones y costumbres.

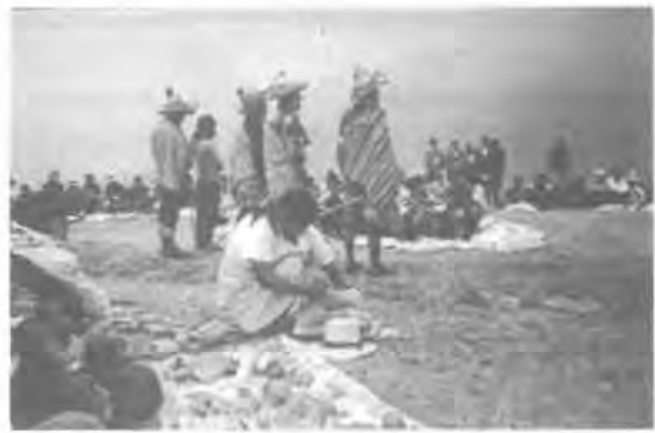

Camachicuy durante la Fiesta del Agua

Los camachicuy son autoridades de origen prehispánico que en San Pedro de Casta y durante la Fiesta del Agua o Champería son encargados de dirigir las faenas de la fimpieza de las acequias. (Foto: psc)

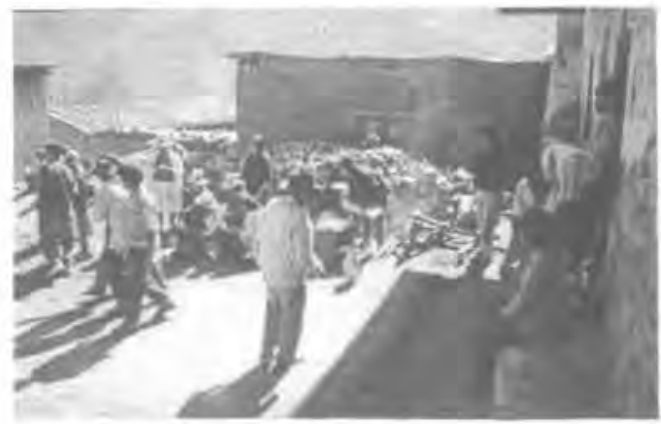

Tuhsma

Es la comida que se realiza descle el día jueves hasta el sábado de la primera semana de octubre. la comunidad se divide en cuatro sparadasn y cada una de ellas recoge viveres para la realización de una kolla común" para todos sus integrantes. Dicho almuerzo tiene fines de confraternidad. 
BREVE DESCRIPCIÕN GEOGRĀFICA, HISTÓRICA, SOCIAL, ECONŌMICA

Y CULTURAL DE LA SIERRA LIMENA: SAN PEDRO DE CASTA

\section{BIBLIOGRAFIAA}

CURATOLA, M. Y SHVA SANTISTEBAN F.

1995 Historiay cultura del Penú, Universidad de Lima, Lima.

ECHEANDIA, Juan

1981 Tenologia y cambios en San Pedra de Casta, Universidad Nacional Mayor de San Marcos, Lima, pp. 17-81

GENTILE LAFAELLE, Margarita

1981 Apuntes para la historia colonial y las fiestas comunales de San Pedro de Castas, en Boletin de Lima, N. 916,17,18, Lima, pp. 177-192

GELLES H., Paül

1984 Aguas, faenasy organización comunal on los Andes: ol caso de San Pedro de Casta. Tesis de Magister, PUCP, Lima.

1986 ksociedades Hidráulicas en los Andes: Algunas perspectivas desde Huarochirin, en Alipanchis, N. ${ }^{\circ}$ 27, pp. 99-144.

JARA SAL.AS, Alfonso

1975 La edwición informal en la connunidad de San Pudro de Casta. Tesis de Licenciatura, Universidad Enrique Guzmán Lavalle, Chosica.

MIILABATRES (ed.)

1995 Atlas geográficay documontal del Perú, Tomo IV, Lima.

OLIVAS WESTON, Marcela

1988 Markahuasi: montana sagrada, CONCYTEC, Lima.

1989 Dehrocasy gentiles, CONCYTEC, Lima, 


\section{Pedro P. Soto Canales}

ROSTWOROWSKI DE DIEZ CANSECO, MARİA

1977 Etniay sociedad; costa peruanta prebispánica, IEP, Lima, 1977.

1978 Señorios indigenas de Lima y Callao, IEP, Lima, 1978.

TELLOROJAS, Julio César y Prospero Miranda

1923 "Wallallo: ceremonias gentilicias", en Revista INKA, volumen 1, N. ${ }^{2}$, Lima, pp. 475-549

\section{ENTREVISTAS}

Sr. Flores Rojas, Herbert

Sr. Medina Obispo,. Walter

St. Rojas Jiménez, Edilberto

Srta. Cisnetos Francia, Isabel

Sra. Bautista Obispo, Herminda
(Alcalde de la comunidad)

(Regidor de la comunidad)

(Presidente comunal)

(Profesora)

(Comedor) 